\title{
CONTROLE DE GRAMÍNEAS EM SOLOS DE VÁRZEA
}

\author{
Francisco de Jesus Vernetti Junior ${ }^{1}$ e André Andres ${ }^{1}$
}

${ }^{1}$ Eng $^{\circ}$. Agrônomo, MSc. Pesquisador da Embrapa Clima Temperado. Caixa Postal 403.

96001-970. Pelotas, RS. vernetti@cpact.embrapa.br

\begin{abstract}
RESUMO
O objetivo deste trabalho foi estudar o efeito de herbicidas e sistemas de cultivo no controle de gramíneas, nas culturas do milho, soja e sorgo implantadas nos sistemas de cultivo mínimo, de semeadura direta e de semeadura convencional, em Planossolo Hidromórfico (resteva de arroz irrigado). O sistema convencional apresentou os melhores resultados para essas culturas, neste tipo de solo. A cultura do sorgo apresentou o melhor desempenho, independentemente do sistema de cultivo utilizado, enquanto o milho teve o pior comportamento e a soja comportamento intermediário. Os herbicidas atrazine (sorgo), s-metolachlor (soja) e atrazine $+s$-metolachlor (milho) controlaram, respectivamente, $80 \%, 70 \%$ e $50 \%$ das invasoras, independentemente da dose empregada. As doses de máxima eficiência técnica foram respectivamente, 3,85 e 3,26 I/ha p.c., para atrazine e $s$-metolachlor, independentemente do sistema de cultivo. Para atrazine $+s$-metolachlor (milho), houve interação de doses e sistemas e as doses de máxima eficiência técnica foram 5,7; 3,9 e 3,65 l/ha p.c., respectivamente, para os sistemas de cultivo mínimo, de semeadura direta e de semeadura convencional.
\end{abstract}

Palavras-chave: sistemas de cultivo, atrazine, s-metolachlor, soja, milho e sorgo.

\section{ABSTRACT}

The aim of this work was to evaluate the effects of herbicides and tillage systems used to control weeds, on corn, soybeans and sorghum crops, cultivated in sequence of irrigated rice. These crops were grown in no-till, minimum tillage and conventional systems in Hidromorfic Soil. The best results for these crops in that kinds of soil were achieved with the conventional system. The sorghum crop stood out that objective, when compared to the other two crops. The atrazine herbicide used in sorghum, attained $80 \%$ of grasses control, while $s$-metolachlor (soybean) and atrazine $+s$-metolachlor (corn) accomplished $70 \%$ and $50 \%$, respectively. The maximum technical efficiency ratio for atrazine and $s$ metolachlor herbicides was, respectively 3.85 and $3.26 \mathrm{I} / \mathrm{ha}$ (c.p.), no matter the tillage system used. There were interactions with ratios and tillage systems when atrazine $+s-$ metolachlor was used (corn). The maximum technical efficiency ratio to that herbicide on minimum tillage was $5.7 \mathrm{l} / \mathrm{ha}$ (c.p.), on no-till was $3.9 \mathrm{l} / \mathrm{ha}$ (c.p.) and on conventional system was $3.65 \mathrm{l} / \mathrm{ha}$ (c.p.).

Key words: tillage systems, atrazine, s-metolachlor, corn, soybeans and sorghum INTRODUÇÃO

A utilização intensiva dos solos de várzea do Rio Grande do Sul, entre outros problemas, gerou um aumento na pressão de infestação de plantas daninhas sobre a cultura do arroz irrigado, principal componente do sistema produtivo. As gramíneas estão 
entre as principais espécies invasoras que ocorrem nestas áreas, em função de sua agressividade e capacidade de disseminação.

A produtividade do arroz irrigado, é dependente do nível de eficiência de controle de plantas daninhas em especial do capim arroz (Echinochloa sp), cuja interferência pode reduzir o rendimento em até $80 \%$. A busca de alternativas que diminuam os custos, mantendo ou melhorando a eficiência do controle de plantas daninhas, está diretamente relacionada a um sistema integrado de práticas agrícolas (Andres et al., 2002). As práticas de controle químico de plantas daninhas devem estar associadas a outras práticas de manejo do sistema produtivo dos solos de várzea. Rotações com espécies como a soja, o milho e o sorgo reduzem significativamente o banco de sementes de plantas daninhas, determinando acréscimos na produtividade de arroz (Ávila et al., 2000; Petrini, et al., 1999 a; Vernetti Jr., et al., 2002; Porto et al., 2000). Dessa forma, o uso de culturas alternativas em rotação com arroz irrigado poderá representar um dos métodos mais eficazes, na recuperação destas áreas, devido à utilização de herbicidas específicos que permitirão o controle de plantas daninhas, inclusive o arroz vermelho (Oryza sativa). Segundo alguns autores (Vernetti Jr. \& Gomes, 1999; Pauletto et al. 1999), os sistemas de semeadura direta e cultivo mínimo diminuem o número de plantas daninhas em geral, quando em comparação com o sistema convencional.

Este trabalho teve por objetivo estudar o efeito de herbicidas e sistemas de cultivo, no controle de gramíneas, nas culturas do milho, da soja e do sorgo, implantadas nos sistemas de cultivo mínimo (CM), de semeadura direta (SD) e de semeadura convencional (SC), em resteva de arroz irrigado.

\section{MATERIAL E MÉTODOS}

O trabalho foi realizado na Estação Experimental de Terras Baixas, da Embrapa Clima Temperado, localizada no Município de Capão do Leão, RS (3152'00"S, 5221'24'W), em Planossolo Hidromórfico Eutrófico com textura franco-arenosa, de pouca profundidade (20 a $40 \mathrm{~cm}$ ), e horizonte $B$ impermeável. Cada um dos experimentos de soja, de milho e de sorgo foi conduzido nas safras 2000/01 e 2001/2002, em delineamento de blocos ao acaso, com parcelas subdivididas e quatro repetições. Mais de 98\% das plantas daninhas, na área experimental, constituíram-se de gramíneas, principalmente capim arroz (Echinochloa sp).

A adubação foi quantificada a partir da análise do solo, seguindo critérios adotados pela Comissão de Fertilidade do Solo RS/SC (1995). A implantação foi efetuada com uma semeadora adubadora Semeato modelo SHM-11. Os sistemas CM, SD e SC, em resteva de arroz, compuseram as parcelas e as doses dos herbicidas as subparcelas. Os herbicidas (Tabela 1) foram aspergidos com pulverizador costal propelido à $\mathrm{CO}_{2}$, munido de 4 bicos DG Teejet 110.015, a pressão constante de 1,8 bar, com volume de calda de $115 \mathrm{l} / \mathrm{ha}$.

No SC foram efetuados aração, gradagem e aplainamento. Nos sistemas SD e $\mathrm{CM}$, após o desenvolvimento das coberturas vegetais, respectivamente, azevém e flora natural, foi realizada a dessecação, através de herbicida de ação total (sulfosate, 5,0 I/ha p.c.).

O efeito dos sistemas de cultivo e herbicidas no controle de gramíneas, foi avaliado 21 dias após a aplicação (DAA), de forma visual, por meio de escala percentual, onde 100 significa controle total das plantas daninhas e zero ausência de danos àquelas (testemunha infestada).

Realizaram-se análises individual e conjunta da variância, do percentual de controle de gramíneas. A comparação entre médias para o fator sistemas de cultivo foi realizada através do teste $F$ para contraste $(P<0,05)$, independentemente das culturas 
utilizadas. Para a comparação de médias dos fatores culturas e herbicidas utilizou-se o teste de Duncan $(\mathrm{P}<0,05)$. Também foi realizada a análise de regressão polinomial para os tratamentos herbicidas, com a finalidade de obter, respectivamente, para cada cultura e sistema, a dose de máxima eficiência técnica (DMET).

\section{RESULTADOS E DISCUSSÃO}

Os sistemas de cultivo apresentaram comportamento semelhante (não diferiram significativamente) no controle de gramíneas para as culturas do milho, da soja e do sorgo.

Ocorreu diferença altamente significativa entre os sistemas de implantação das culturas utilizadas em rotação com arroz irrigado, quanto à percentagem de controle de gramíneas (Figura 1). Independentemente das culturas, doses e herbicidas não houve diferença significativa entre os sistemas SD e CM, os quais apresentaram os menores percentuais de controle. O sistema SC foi significativamente superior aos sistemas SD e CM quanto ao controle das gramíneas. Entretanto, o controle exercido pelo SC, de aproximadamente $70 \%$ foi baixo.

A maioria das espécies silvestres desenvolve mecanismos para impedir a germinação, quando as sementes não estão próximas a superfície do solo, garantindo assim sua sobrevivência (Franco et al., 2001). Ao se realizarem arações e gradagens para o SC das culturas da soja, milho e sorgo, as sementes de plantas daninhas que se encontram em maior profundidade, ficam (ou são transportadas ou depositadas) mais próximo à superfície, viabilizando sua germinação, que normalmente é mais uniforme nestas condições e, consequentemente, permite uma ação mais eficaz dos herbicidas utilizados na soja, milho e sorgo.

Também ocorreram diferenças altamente significativas, entre as culturas quanto ao percentual de controle de gramíneas sendo os melhores efeitos obtidos, em ordem decrescente, com sorgo, soja e milho (Figura 2). No milho os tratamentos herbicidas foram pouco eficientes, controlando apenas $50 \%$ das plantas daninhas (Figura 3 ). O maior percentual de controle de plantas daninhas, obtido com a cultura do sorgo, de $80 \%$, esta de acordo com os resultados obtidos por Petrini et al. (1999 b).

$\mathrm{Na}$ cultura do milho ocorreu interação significativa entre doses e sistemas de implantação, quanto ao percentual de controle de gramíneas.

As doses de máxima eficiência técnica (DMET) do herbicida atrazine $+s$ metolachlor foram, 5,7; 3,9 e 3,65 I/ha p.c., respectivamente, para os sistemas CM, SD e SC. Esse diferencial de doses, entre os sistemas de cultivo, demonstra o efeito do baixo controle cultural do milho sobre as plantas daninhas. Evidentemente, há que se considerar o aspecto da baixa população inicial obtido nesta cultura, função do excesso de chuvas após a implantação do estudo que afetou também a performance do herbicida. Entretanto, em termos econômicos supõe-se que a menor dose no sistema de semeadura convencional implica em redução de custos, alem de favorecer o ambiente.

Nas culturas da soja e do sorgo o fator dose foi altamente significativo no controle de gramíneas, não apresentando interação com os sistemas de cultivo (Figura 4). A DMET do herbicida $s$-metolachlor, utilizado na cultura da soja foi 3,26 I/ha p.c. Na cultura do sorgo, a DMET, para o herbicida atrazine foi de 3,85 I/ha p.c.

\section{CONCLUSÕES}

O cultivo convencional de milho, soja e sorgo, em restevas de arroz irrigado, é mais eficiente no controle de gramíneas, comparativamente ao cultivo mínimo e semeadura direta. 
O herbicida atrazine reduz a infestação de gramíneas, principalmente o capim arroz (Echinochloa sp), na cultura do sorgo em solos de várzea, independentemente do sistema de cultivo.

A dose de maior eficiência técnica para o herbicida atrazine $+s$-metolachlor, nos sistemas de cultivo mínimo, semeadura direta e semeadura convencional, na cultura do milho é, respectivamente 5,7, 3,9 e 3,65 I/ha p.c.

A dose de maior eficiência técnica para o herbicida s-metolachlor, na cultura da soja, é 3,26 I/ha p.c.

O herbicida atrazine mostrou-se eficiente para o controle de gramíneas invasoras na cultura do sorgo, implantada em resteva de arroz irrigado, independentemente da dose empregada.

A dose de maior eficiência técnica para o herbicida atrazine na cultura do sorgo é de 3,85 I/ha p.c.

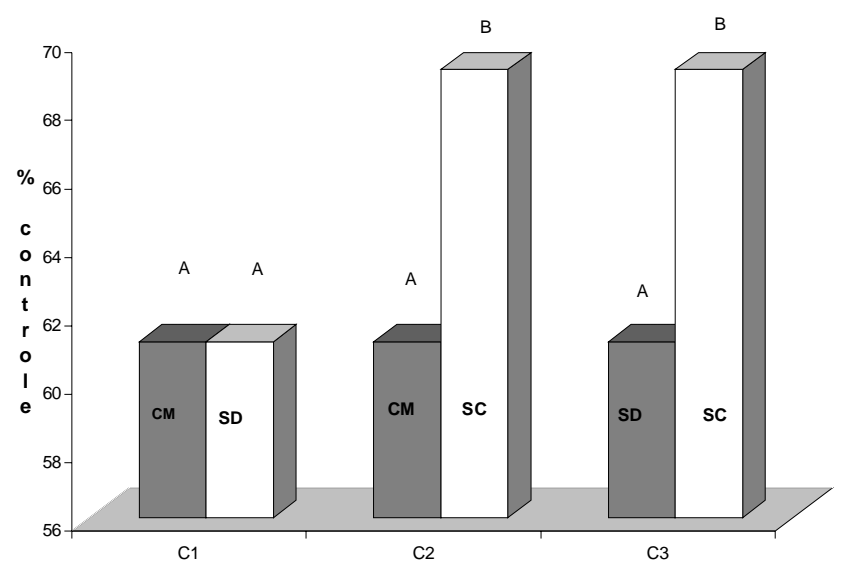

Figura 1. Contrastes entre sistemas de cultivo em relação ao percentual de controle de gramíneas aos 21 dias após a aplicação (média de 2 anos). $C_{1}-$ cultivo mínimo (CM) e semeadura direta (SD); $\mathrm{C}_{2}-\mathrm{CM}$ e semeadura convencional (SC); $\mathrm{C}_{3}-$ SD e SC. Médias com a mesma letra não diferem pelo teste de $F(P<0,05)$. Embrapa Clima Temperado. Pelotas, RS, 2002.

Figura 2. Percentagem de controle de gramíneas exercido pelas culturas do milho, soja e sorgo em resteva de arroz irrigado aos 21 dias após a aplicação (média de 2 anos). Mẻdias ce letra não diferem pelo teste de Duncan $(P<0,05)$ Embrapa Clima $\quad$ do. Pelotas, RS, 2002.

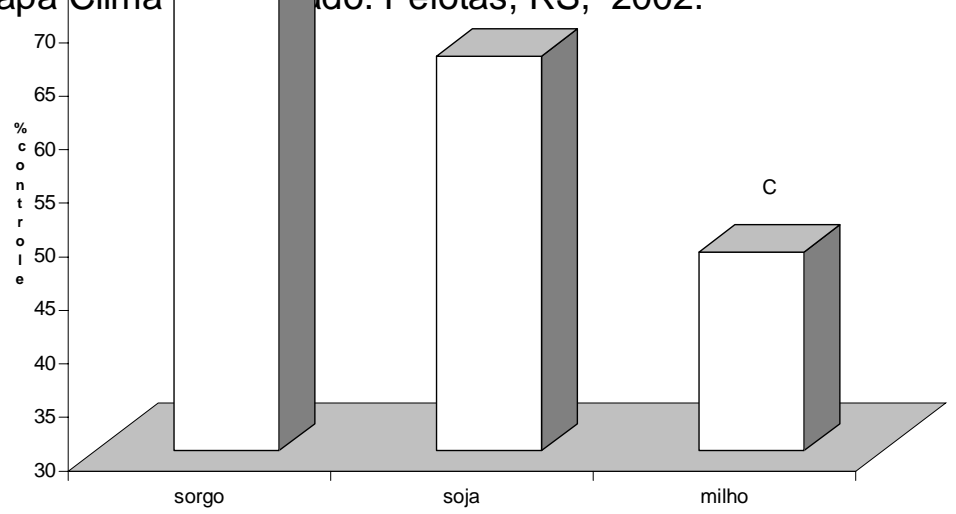




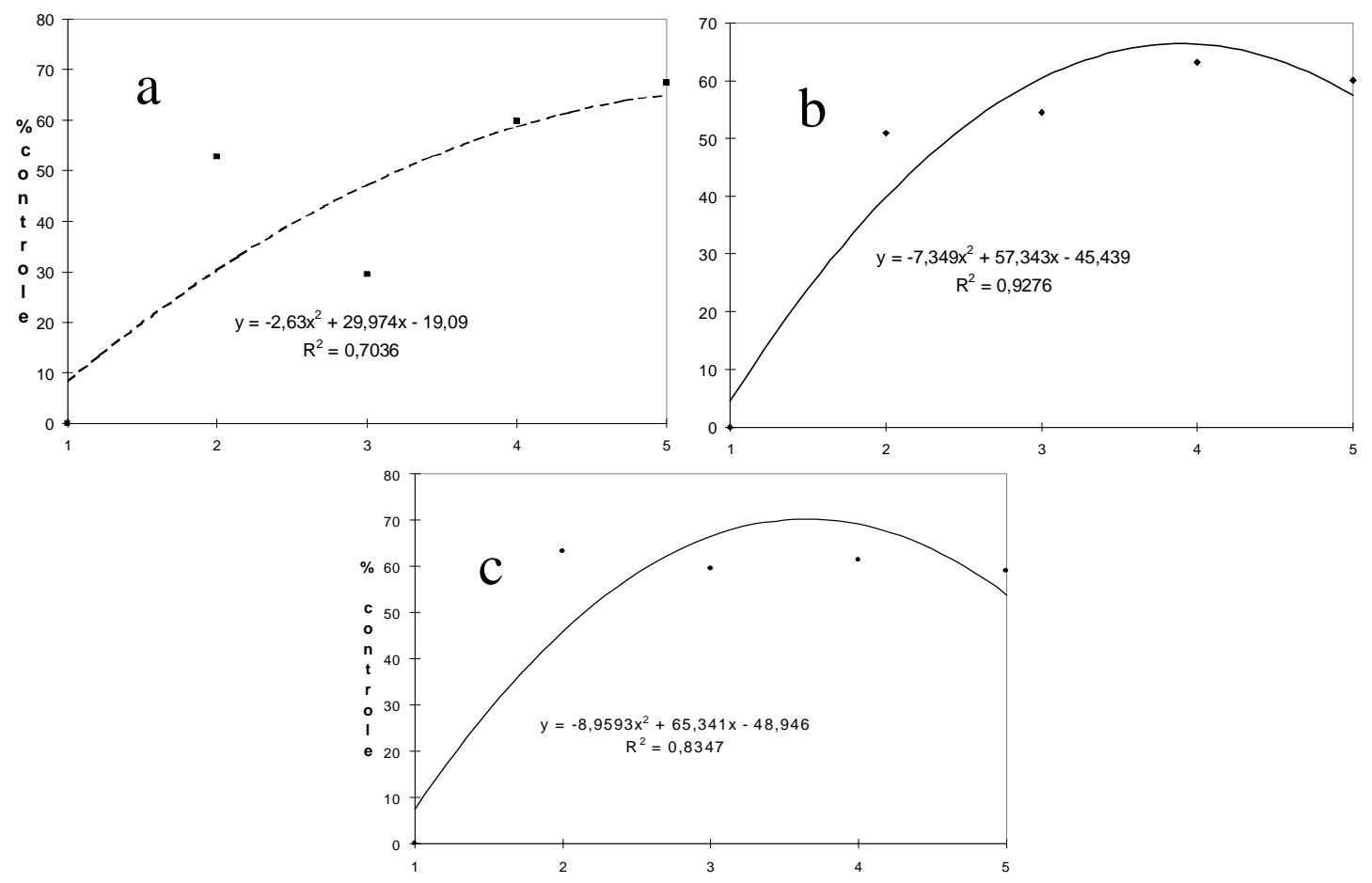

Figura 3. Percentagem de controle de plantas daninhas na cultura do milho em função de sistemas de cultivo $(\mathrm{a}-\mathrm{CM}$; b - SD; $\mathrm{c}-\mathrm{SC})$ e de doses de atrazine $+s$ metolachlor aos 21 dias após a aplicação (média de 2 anos). Embrapa Clima Temperado. Pelotas, RS, 2002.
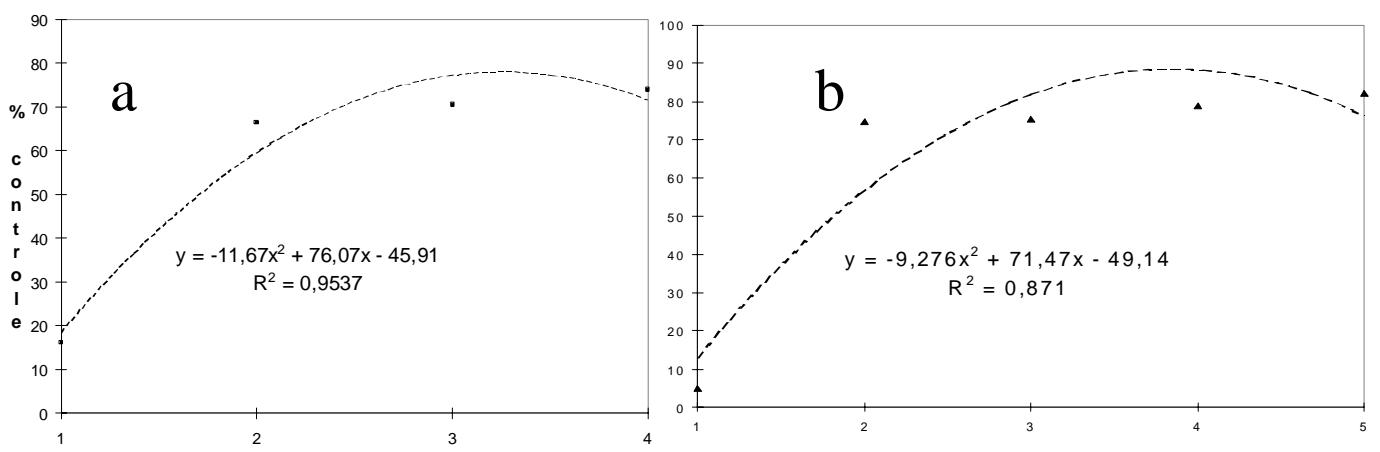

Figura 4. Percentagem de controle de plantas daninhas na cultura da soja (a) e do sorgo (b), independentemente de sistemas de cultivo e em função das doses de herbicida aos 21 dias após a aplicação (média de 2 anos). Embrapa Clima Temperado. Pelotas, RS, 2002.

Tabela 1. Herbicidas e doses utilizados para o controle de gramíneas em aplicação de pré-emergência, nas diversas culturas em resteva de arroz irrigado. Embrapa Clima Temperado. Pelotas, RS, 2002. 


\begin{tabular}{cccc}
\hline Culturas & Doses & Tratamentos & $\begin{array}{c}\text { Ingrediente ativo } \\
\left(\mathrm{g} \cdot \mathrm{ha}^{-1}\right)\end{array}$ \\
\hline \multirow{4}{*}{ Milho } & $\mathrm{H}_{1}$ & testemunha infestada & - \\
& $\mathrm{H}_{2}$ & atrazine + s-metolachlor & $1110+841$ \\
& $\mathrm{H}_{3}$ & atrazine + s-metolachlor & $1295+1015$ \\
& $\mathrm{H}_{4}$ & atrazine + s-metolachlor & $1480+1160$ \\
& $\mathrm{H}_{5}$ & atrazine + s-metolachlor & $1665+1305$ \\
\hline \multirow{4}{*}{ Sorgo } & $\mathrm{H}_{1}$ & testemunha infestada & - \\
& $\mathrm{H}_{2}$ & atrazine & 1500 \\
& $\mathrm{H}_{3}$ & atrazine & 2000 \\
& $\mathrm{H}_{4}$ & atrazine & 2500 \\
Soja & $\mathrm{H}_{5}$ & atrazine & 3000 \\
& $\mathrm{H}_{1}$ & Testemunha infestada & - \\
& $\mathrm{H}_{2}$ & $s$-metolachlor & 1440 \\
& $\mathrm{H}_{3}$ & $s$-metolachlor & 1680 \\
& $\mathrm{H}_{4}$ & $s$-metolachlor & 1920 \\
\hline
\end{tabular}

\section{LITERATURA CITADA}

ANDRES A.; VERNETTI JR, F.de J.; SCHWANKE, A.L.M.; CONCENÇO, G. Uso de sistemas de cultivo e herbicidas para manejo de gramíneas nas culturas do sorgo e milho em rotação com arroz irrigado. In: CONGRESSO BRASILEIRO DA CIÊNCIA DAS PLANTAS DANINHAS,23. 2002, Gramado. Resumos. Londrina: SBCPD/Embrapa Clima Temperado, 2002. p.303.

ÁVILA, L.A.; MARCHEZAN, E.; PORTO, M.P.; ANDRES, A.; SILVA, R.P. da; BRUNDT, A.L. Cultivares de milho em várzea na Depressão Central do Rio Grande do Sul. In: REUNIÃO TÉCNICA ANUAL DO MILHO, 45; REUNIÃO TÉCNICA DO SORGO, 28. Pelotas, 2000. Anais... Pelotas: Embrapa Clima Temperado, 2000. p. 176-182. (Embrapa Clima Temperado. Documentos ,70).

COMISSÃO DE FERTILIDADE DO SOLO - RS/SC. Recomendação de adubação e calagem para os estados do Rio Grande do Sul e Santa Catarina. 3 ed. Passo Fundo, SBCS - Núcleo Regional Sul, 1995, 224 p.

FRANCO, D.F.; MAGALHÃES JR, A.M.; ANDRES, A.; PETRINI, J.A. Comportamento das sementes de arroz-vermelho no solo. In: CONGRESSO BRASILEIRO DE ARROZ IRRIGADO, 2; REUNIÃO DA CULTURA DO ARROZ IRRIGADO, 24, 2001, Porto Alegre.. Anais. Porto Alegre: Instituto Rio Grandense do Arroz .2001 . p. 680-682.

PAULETTO, E.A.; GOMES, A. da S.; SOUSA,R.0.; PETRINI, J. A. Manejo de Solos de Várzea. In: GOMES, A. da S.; PAULETTO, E.A. Manejo de solos de várzea. In: Manejo do solo e da água em áreas de várzea. Pelotas: Embrapa Clima Temperado, 1999. p.61-87.

PETRINI, J.A.; RAUPP, A.A.A.; PARFITT, J.M.B.; VERNETTI JR, F. de J.; FRANCO, D.F.; GASTAL, M.F.da C.; REIS, J.C.L.; AZAMBUJA, I.H.V. Estratégias para redução do arroz vermelho no solo. In: FAGUNDES, P.; MAGALHÃES JR. A.M.. Aspectos tecnológicos da produção agropecuária em áreas de arroz irrigado do Rio Grande do Sul. Pelotas: Embrapa Clima Temperado, 1999 a. p.78-84 (Embrapa Clima Temperado. Documentos, 65).

PETRINI, J.A.; RAUPP, A.A.A.; FRANCO, D.F. Efeito alelopático de sorgo granífero (Sorghum bicolor L. Moench) sobre a germinação de sementes de arroz vermelho 
(Oryza sativa L.) In: CONGRESSO BRASILEIRO DE ARROZ IRRIGADO, 1; REUNIÃO DA CULTURA DO ARROZ IRRIGADO, 23, 1999, Pelotas.. Anais. Pelotas: Embrapa Clima Temperado, 1999 b . p. 719-721.

PORTO, M.P.; WINKLER, E.I.; PARFITT, J.M.B.; SILVA, C.A.S.; FRANCO J.C.B. Comportamento de variedades de milho irrigadas por inundação em solo hidromórfico, em Bagé, RS, no ano agrícola 1999/2000. In: REUNIÃO TÉCNICA ANUAL DO MILHO, 45; REUNIÃO TÉCNICA DO SORGO, 28. Pelotas, 2000. Anais... Pelotas: Embrapa Clima Temperado, 2000. p. 217-223. (Embrapa Clima Temperado. Documentos ,70).

VERNETTI JR, F. de J.; GOMES, A.da S. Plantio Direto: uma opção de manejo para a produção agrícola sustentável. Pelotas: Embrapa Clima Temperado, 1999. 69 p. (Embrapa Clima Temperado. Documentos, 58).

VERNETTI JR, F.de J.; ANDRES A.; SCHWANKE, A.L.M.; CONCENÇO, G. Controle de gramíneas na cultura da soja em rotação com arroz irrigado, em três sistemas de cultivo. In: CONGRESSO BRASILEIRO DA CIÊNCIA DAS PLANTAS DANINHAS, 23. 2002, Gramado. Resumos. Londrina: SBCPD/Embrapa Clima Temperado, 2002. p.408. 